Brit. J. prev. soc. Med. (1957), 11, 79-89

\title{
A CRITICAL EXAMINATION OF THE REPUTED PRIMARY INFLUENCE OF ABO PHENOTYPE ON FERTILITY AND SEX RATIO
}

\author{
BY \\ J. H. EDWARDS \\ From the Department of Social Medicine, University of Birmingham
}

Within the last decade, statistical evidence has accumulated that the ABO blood groups have selective influences other than those due to mismatched or unavailable transfusions, and an increasing literature has convincingly demonstrated a primary influence on at least one group of diseases in adults. Publications on the influence of the $\mathrm{ABO}$ phenotypes on fertility and sex ratio have made similar claims of apparent selective influences inexplicable by chance, and such claims have been widely quoted (British Medical Journal, 1954), and have been promoted to the attention of geneticists in the Bateson lecture on morphism (Huxley, 1955).

\section{Some Difficulties of Statistical Analysis}

The problem of analysis in the light of the exclusive and exhaustive classes of prior hypotheses of heterosis and foetal incompatibility would present considerable inferential problems even with a diallelic system, a Poissonian distribution of family size, random sampling, and a well miscegenated population. In practice, most data refer to triallelic or tetra-allelic systems; the distribution of family sizes is far from Poissonian; and random sampling has rarely been achieved. Populations with facilities for blood grouping are mostly cosmopolitan, with appreciable proportions of unusual blood group distribution (for example, Jews, Irish, or Negroes), and such minorities usually have different views, abilities, or opportunities in relation to their standard of living and family size.

The heterogeneity due to these factors is such that, in conjunction with statistical methods which ignore it, or which are assumed appropriate on the grounds that they have been helpful when applied to experimental data or to observational data consisting of far fewer observations, almost every set of data published can be analysed to show evidence of "significant" differences in fertility. Such differences would be expected to arise from the heterogeneity of the data itself, and the separation of the side-effects of a gene from the effects of other genes with which it is associated cannot usually be made on information implicit within any single set of data. Significance tests may be necessary, but they are certainly not sufficient, as evidence of any such effect.

While this multiplicity of claims is such as usually initiates the healthy development of a new subject, and while the task of the critic is comparatively easy, in that he has the advantage of comparing any two papers at least one of whose authors could not have read the other, it would appear to be worth while to try to analyse some of the inherent difficulties and to attempt to advance constructive suggestions.

Firstly, in the absence of any well-grounded prior hypotheses, other than the vague and contradictory expectations of foetal incompatibility and heterozygote advantage, interpretation must largely be based on posterior hypotheses. Consequently, tests of significance must be based on the whole data, and this tends to shield any heterogeneity limited to a few of many class frequencies. As it is quite possible that there may be systematic discrepancies limited to only one or two of many class frequencies, as would be expected in the various Rhesus parent-child combinations, it would seem valid to apply also a significance test to those classes most discrepant from the mean. As in a manyclassed contingency table the ratio of the square of a discrepancy to its expectation $\left(d^{2} / e\right)$ has, on the null hypothesis, the probability of a random variate from a normal population of zero mean and unit variance, significance tests may easily be applied using the probability distribution of the extreme deviates; these have been tabulated (May, 1952). Although only approximate, such methods would seem preferable to the highly fallacious methods of testing those classes with the most extreme difference for independence. There would, of course, 
be a probability of almost pn of wrongly rejecting a null hypothesis with $n$ independent tests at the $p$ th level.

Secondly, conventional significance tests seem unsuited to such data. Methods dependent on the sampling distribution of attributes, as $\chi^{2}$, may be useful when small numbers of observations are being analysed and fairly gross distortions of proportionality are necessary for the rejection of the null hypothesis, but are not suited to observational material in man where many thousands of cases are being compared. It is doubtful whether any null hypothesis of association of attributes tested on observational data derived from, say, 10,000 men would survive rejection at anything approaching $1-p$ times at the $p$ th level of significance.

Most significance tests, including those dependent on the probability distribution of $\chi^{2}$, are comparisons of the ratio of the square of a discrepancy to its variance, so that, as the size of the sample increases, any bias increases this ratio in proportion to the sample size. This leads to the paradox that the larger the series, the greater the caution necessary in accepting any apparent rejection of the null hypothesis. Consider a small systematic error $\gamma$. If the numbers are large, the discrepancy in a sample of number $n$ will be $n \gamma$, with variance approximately $n$. Conventionally, it will be regarded as significant if $n \gamma$ exceeds $2 \sqrt{ } n$.

When $\gamma>\frac{2}{\sqrt{ } n}$, this will occur "usually". When $\gamma=\frac{1}{\sqrt{ } n}$, this will occur with a probability of about 16 per cent., and, when $\gamma=\frac{1}{2 \sqrt{ } n}$, of about $7 \cdot 3$ per cent.

For example, in a series of 10,000 cases, a 2 per cent. systematic error would "usually" appear significant at the 5 per cent. level, and in 60,000 cases at the one in a million level.

This is, of course, not a criticism of such methods of analysis as are designed to detect such discrepancies, but merely a demonstration of the confidence of freedom from small systematic influences which must be assumed before using such tests. The belief that the difficulty can be overcome by using higher levels of significance is not only fallacious, but harmful, in that very highly significant discrepancies are less readily dismissed as statistical artefacts.

In view of the obvious racial, social, and religious sub-grouping in man, it is doubtful whether such methods are applicable to his reproduction. Apart from errors of paternity and blood-grouping, misinterpretation of data may readily arise from such correlation nets as: Irish ancestry, high proportion group $\mathrm{O}$, Catholicism, absence of contraception, larger families: Jewish faith, high proportion group $B$, atypical morbidity experience, absence of contraception, Niddah, highly assortative mating; Negro facies, high proportion group B, large family size, high neo-natal death rate.

And this misinterpretation will often appear to be confirmed by data from other regions. Further, race, religion, marital status, and parity may appreciably influence liability to become a blood donor.

A simple solution to some of the problems of a significance test which would be insensitive to small systematic bias would appear to be Woolf's efficient test of proportionality in a $2 \times 2$ table (Woolf, $1955)$, provided the null hypothesis is only regarded as rejected when the fiducial limits of this estimate exclude, not unity, but some arbitrarily determined range, say $0.95-1.05$, which is considered unlikely to be exceeded by the bias which cannot be excluded. An essential, and unique, feature of this method is the possibility of combining data from diverse populations, without introducing bias or losing information. Haldane (1956) has published a refinement of Woolf's method which is very simple and reduces any bias due to the asymetrical sampling errors of small numbers. Data should therefore be subdivided as often as practicable: religion may be suggested as a simple attribute which is usually recorded on hospital notes (Penrose, 1955). This analysis will not detect very small discrepancies which are, by their nature, probably indiscernible in man. The impossibility of detecting small differences, while possibly discouraging the further accumulation of data on the $\mathrm{ABO}$ phenotypes, in which fertility is assessed by enumeration of the children of the fertile, should not discourage the collection of other data. Appreciable differences in the relative liability of different phenotypes may well occur in certain particular forms of fertility impairment or in sterility, and yet have escaped recognition. In these cases, Woolf's method of analysis would be particularly easy to apply.

As there are $\frac{1}{2} n(n-1)$ internal comparisons which can be made in an $n \times 2$ table (i.e. two populations classified into $n$ phenotypes), the arbitrary adoption of some standard which would reduce the number of comparisons to $n-1$ would seem desirable. The recessive phenotypes (such as $\mathrm{O}, d / d$ ) would seem in general most suitable, being fairly frequent in most races and of unique genotype. This solution is only applicable to problems which can be presented as an $n \times 2$ table, for example in relation to disease, to the sex ratio, and to sterility. It is not applicable to investigations involving 
gradatiơns in fertility. In such cases Student's " $t$ " test is frequently used, but in view of the very poor approximation of family size distribution to normality or even to a Poissonian distribution, it would seem most unsuitable. The difficulty may be overcome with some loss of information, by dividing families into those above and below their median size, or some other percentile. More refined tests would require very exacting definitions of fertility, if equally reasonable tests were not to give opposing results.

Any absence of acceptable evidence is, of course, not negative evidence. A difference in fertility too slight to demonstrate (for example 1 per cent.) would probably be sufficient to have maintained this genetic variation throughout or beyond the time of man. Even the fairly intense selection against some heterozygotes of the Rhesus phenotypes would probably not be evident from statistical studies in the absence of a hypothesis derived from anecdotal evidence. Indeed, paradoxical discrepancies have been described in statistical studies relevant to such hypotheses (Glass, 1950).

A trend evident in many of these studies is that, while they have been explicitly made as a result of the theoretical necessity of differences with respect to genotype fitness (though not necessarily in phenotype fitness) to maintain such variation, the hypotheses advanced to explain such differences as have been claimed have usually been such as would lead to instability if they were real.

\section{A Critical Examination of Published Work claiming an Association between Blood Group and Fertility.}

Seven widely-quoted publications claim to have demonstrated an association between blood group and fertility.

(1) By assembling data from the literature, Waterhouse and Hogben (1947) inferred an intense selection against Group A foetuses of Group $\mathrm{O}$ mothers. This conclusion was criticized by Bennett and Brandt (1954), who considered that the differences in birth rank of Group $A$ and Group $O$ children of $A / O$ marriages (Group A husband and Group $O$ wife) and the differences in the proportions of Group $O$ and Group A children of $\mathrm{A} / \mathrm{O}$ and $\mathrm{O} / \mathrm{A}$ marriages were "not other than trivial". Their rejection of the primary hypothesis of progressive maternal inhospitality to Group A foetuses by Group $\mathrm{O}$ mothers is on grounds of undisturbed birth order, and not, as is sometimes stated, of heterogeneity within the data.
Although the tests used by Bennett and Brandt are technically efficient, the absence of any significant discrepancy does not necessarily imply that the data do not contain evidence of selection through foetal incompatibility. Firstly, Haldane and Smith's efficient test of birth order disturbance on which Bennett and Brandt base their claim is a test for consistent trend. Consequently, it is not efficient as a test of trend in the birth order disturbances of later-born children if first-born are included and if they are (as is suggested by the histograms published by Waterhouse and Hogben) particularly prone to bastardy. If bastardy is far commoner in the firstborn, the custom, once practised in the Highlands of Scotland (see Boswell's Journal of a Tour of the Hebrides with Samuel Johnson, 1786), of excluding the first-born from any ancestral status might be followed with advantage. Secondly, in relation to their claim of no significant disturbance in segregation ratio, it cannot be assumed that segregation recorded among the children of a mother of recessive group implies that the husband is heterozygous. The presence of a few large families, in which the husband was homozygous for the dominant gene, and in which one child was a bastard of recessive group, would greatly bias any data on segregation.

As an example of bias due to mistaken paternity, consider a large number of families, each consisting of $n$ children of Group $\mathrm{O}$ mothers whose husbands are Group A, and let a small proportion $(\alpha)$ of children be not fathered by their mother's husband. If all families which contain a member of Group B or $\mathrm{AB}$ are excluded, one may consider the gene conferring the $B$ antigen to be excluded from the universe under discussion.

Let the gene frequencies be $p$ and $r$. The proportion of $\mathrm{A} / \mathrm{O}$ marriages in which the husband is homozygous is $\frac{p^{2}}{1-r^{2}}$, and in almost $\alpha r n$ families there will be apparent segregation.

There will be $\alpha r n^{2} \frac{p^{2}}{1-r^{2}}$ children of families containing a bastard; of these children $\alpha r n \frac{p^{2}}{1-r^{2}}$ will be of Group $O$ and $\alpha r n(n-1) \frac{p^{2}}{1-r^{2}}$ of Group A.

If we ignore the relatively small bias from bastardy in families in which the husband is heterozygous, the segregation ratio (ratio of Group A to Group $\mathbf{O}$ 
children in the families which segregate) will be:

$$
\frac{\frac{n p r(1-\alpha)}{1-r^{2}}+\frac{\alpha n p^{2} r(n-1)}{1-r^{2}}}{\frac{n p r(1-\alpha)}{1-r^{2}}+\frac{\alpha n p^{2} r}{1-r^{2}}}=\frac{(1-\alpha)+\alpha p(n-1)}{(1-\alpha)+\alpha p}
$$

If, as is probably common in European data, $p=0 \cdot 3, n=4, \alpha=0.05$, this ratio would be 1.03 . In O/A marriages, the bias from bastardy would be far less, as spurious segregation could not occur.

Serious bias may also arise from grouping errors, particularly as they are usually systematic, and are commoner in children, particularly in young children (children of higher birth rank). Consider the simple universe defined above, ignoring bastardy. Assume the parents accurately grouped, and let the proportion of children of Group A misgrouped as $\mathrm{O}$ be $\beta$.

Then, of the A/O or O/A matings, there will be $\frac{p^{2}}{1-r^{2}}$ families of homozygous parents, of which almost $\frac{\beta n p^{2}}{1-r^{2}}$ will be regarded as segregating, so that the segregation ratio will be:

$\frac{\frac{n p r(1-\beta)}{1-r^{2}}+\frac{\beta n p^{2}(n-1)}{1-r^{2}}}{\frac{n p r(1-\beta)}{1-r^{2}}+\frac{\beta n p^{2}}{1-r^{2}}}=\frac{r(1-\beta)+\beta p(n-1)}{r(1-\beta)+\beta p}$

If, for example $r=0 \cdot 7, p=0 \cdot 3, n=4, \beta=0 \cdot 05$, this ratio will be $1 \cdot 04$.

This apparent segregation, due to either bastardy, or grouping errors, or both, could clearly lead to considerable bias in interpretation.

(2) Allan (1953) reviewed the data of Waterhouse and Hogben and, concluding "that some other difference must be sought for the curious differences in fertility found in the sample", proposed an ingenious hypothesis of "inverse fertility", the fertility of each phenotype being supposed to differ from the mean by an equal and opposite amount in the two sexes. Before considering the evidence for this hypothesis, it is of interest to consider whether there is any justification for regarding these differences as curious.

One approach to this problem, which has sometimes been employed, is to test the combined null hypotheses of random mating and equal fertility by a test of unreasonableness of proportions or a test of independence relative to the marginal totals, assuming $(n-1)^{2}$ degrees of freedom where there are $n$ phenotypes. This, however, is fallacious; in the presence of random mating, and of ascertainment independent of family size, the modal value of $\sum \frac{d^{2}}{e}$, where $e$ is the expected number and $d$ that number less the observed number, is not $(n-1)^{2}$ but $f(n-1)^{2}$, where $f$ is the mean number of children per marriage. If $f=3 \cdot 3$ and $n=4$, this modal value will exceed the very highly significant value of $\chi^{2}(\vartheta)$.

When information on relative fertility is provided only by those children who are in excess of a minimum number necessary for inclusion in the data, that minimum number, usually one, should be subtracted from all family sizes. A possible shortcoming of such data is that, if apparent sterility, that is childlessness at the time of collection of the data, differs in degree, rather than in nature, from relative infertility, series from which childless marriages are excluded may reveal apparent trends in fertility diametrically opposed to any which actually exist.

If the distribution of family size were Poissonian, the significance of any discrepancy from the expectation of uniform fertility could easily be tested, since

$$
\sum_{1 \ldots n} \frac{d^{2}}{e}
$$

would be distributed as $\chi_{(n-2)}^{2}$.

Waterhouse and Hogben have published the family size of all O/A and A/O marriages, of which there were 453 with 1,068 children excluding the first, giving a mean of $2 \cdot 36$ and variance $8 \cdot 90$. It may reasonably be supposed, therefore, that in the data as a whole, the variance considerably exceeds the mean. Consequently, on the null hypothesis, the probability of obtaining a value of

$$
\sum \frac{d^{2}}{e}
$$

or higher will not be less than the probability of exceeding $\chi^{2}{ }_{(n-2)}$.

Even if "significant differences" could be demonstrated, these data would not necessarily imply any primary effect of blood group on fertility. In fact, even after excluding one child from each family, the differences in fertility (Tables I and II, opposite) are not beyond the reasonable expectations of chance and hardly form sufficient evidence for rejection of the null hypothesis. 
TABLE I

NUMBER OF MARRIAGES AND CHILDREN DUE TO THEM IN EACH CLASS RELATIVE TO THE ABO SYSTEM

\begin{tabular}{|c|c|c|c|c|c|c|}
\hline \multirow{2}{*}{\multicolumn{2}{|c|}{$\begin{array}{l}\text { Blood } \\
\text { Group of } \\
\text { Husband }\end{array}$}} & \multicolumn{4}{|c|}{ Blood Group of Wife } & \multirow{3}{*}{$\begin{array}{r}\text { Total } \\
542 \\
1,841\end{array}$} \\
\hline & & \multirow{2}{*}{$\begin{array}{l}0 \\
225 \\
779\end{array}$} & \multirow{2}{*}{$\begin{array}{l}A \\
244 \\
835\end{array}$} & \multirow{2}{*}{ 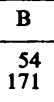 } & \multirow{2}{*}{$\begin{array}{r}\text { AB } \\
19 \\
56\end{array}$} & \\
\hline $\mathbf{O}$ & $\begin{array}{l}\text { Marriages } \\
\text { Children }\end{array}$ & & & & & \\
\hline $\mathbf{A}$ & $\begin{array}{l}\text { Marriages } \\
\text { Children }\end{array}$ & $\begin{array}{l}209 \\
686\end{array}$ & $\begin{array}{l}189 \\
599\end{array}$ & $\begin{array}{r}63 \\
196\end{array}$ & $\begin{array}{l}28 \\
96\end{array}$ & $\begin{array}{r}489 \\
1.577\end{array}$ \\
\hline $\mathbf{B}$ & $\begin{array}{l}\text { Marriages } \\
\text { Children }\end{array}$ & $\begin{array}{r}66 \\
229\end{array}$ & $\begin{array}{r}59 \\
210\end{array}$ & $\begin{array}{l}17 \\
62\end{array}$ & $\begin{array}{r}8 \\
30\end{array}$ & $\begin{array}{l}150 \\
531\end{array}$ \\
\hline AB & $\begin{array}{l}\text { Marriages } \\
\text { Children }\end{array}$ & $\begin{array}{l}23 \\
72\end{array}$ & $\begin{array}{l}20 \\
80\end{array}$ & $\begin{array}{r}6 \\
14\end{array}$ & $\begin{array}{r}9 \\
24\end{array}$ & $\begin{array}{r}58 \\
190\end{array}$ \\
\hline Total & $\begin{array}{l}\text { Marriages } \\
\text { Children }\end{array}$ & $\begin{array}{r}523 \\
1,766\end{array}$ & $\begin{array}{r}512 \\
1,724\end{array}$ & $\begin{array}{l}140 \\
443\end{array}$ & $\begin{array}{r}64 \\
206\end{array}$ & $\begin{array}{l}1,239 \\
4,139\end{array}$ \\
\hline
\end{tabular}

Heterospecific marriages are shown in bold type.

TABLE II

VALUES OF $d^{2} / e$ FOR FAMILY SIZE (LESS ONE CHILD) ACCORDING TO PARENTAL BLOOD GROUP

$e$ represents the number of children expected on the null hypothesis and $d$ the difference between observed and expected numbers

(From data assembled by Waterhouse and Hogben, 1947)

\begin{tabular}{|c|c|c|c|c|c|c|}
\hline \multirow{2}{*}{$\begin{array}{l}\text { Blood } \\
\text { Group of } \\
\text { Husband }\end{array}$} & \multicolumn{6}{|c|}{ Blood Group of Wife } \\
\hline & $\mathbf{O}$ & $\mathbf{A}$ & B & $\mathbf{A B}$ & \multicolumn{2}{|c|}{ All Groups } \\
\hline $\mathbf{O}$ & $1 \cdot 423$ & 0.693 & 0.698 & $1 \cdot 255$ & $0 \cdot 729$ & \multirow{4}{*}{$6 \cdot 17$} \\
\hline $\mathbf{A}$ & $0 \cdot 304$ & $2 \cdot 369$ & $1 \cdot 418$ & 0.092 & $2 \cdot 795$ & \\
\hline B & 0.468 & $1 \cdot 205$ & 0.682 & 0.575 & $2 \cdot 545$ & \\
\hline $\mathbf{A B}$ & 0.433 & $3 \cdot 717$ & $2 \cdot 598$ & $1 \cdot 749$ & $0 \cdot 104$ & \\
\hline \multirow[t]{2}{*}{ All Groups } & 0.291 & $0 \cdot 155$ & $1 \cdot 859$ & 0.406 & \multirow{2}{*}{\multicolumn{2}{|c|}{$19 \cdot 68$}} \\
\hline & \multicolumn{4}{|c|}{$2 \cdot 71$} & & \\
\hline
\end{tabular}

When $\chi^{2}(16)=19.68,0.1<p<0.2$

$\chi_{(8)}^{2}=6.17,0.02<p<0.05$

$\chi^{2}(2)=2 \cdot 71,0 \cdot 2<p<0 \cdot 3$

It would seem, therefore, that Allan's hypothesis receives little support from data in which the body of the table shows no significant differences in fertility and in which the marginal totals do not both differ significantly from expectation.

Allan has suggested that such inversions of fertility with sex may be a sufficient reason for the establishment and persistence of such variation, and it is of interest to consider this sufficiency on a simple model.

Consider such genotypes $A_{i j}$ as are determined by autosomal alleles $A_{1}, A_{2}, \ldots \ldots A_{n}$, having frequencies $x_{1}, x_{2}, \ldots \ldots x_{n}$, and let the genotypes $m A_{i j}$ and $f \mathrm{~A}_{i j}$, where $m$ and $f$ imply male and female, have fertilities $1+{ }_{m} l_{i j}$ and $1+{ }_{f} l_{i j}$, and let the combined fertility of a mating pair be the sum of the independent fertilities.
Allan's hypothesis appears to imply:

$$
\left(1+m l_{i j}\right)=\left(1-{ }_{f} l_{i j}\right) .
$$

Matings between genotypes which are alike will have relative fertility:

$$
\begin{aligned}
& \left(1+m l_{i j}\right)+\left(1+f l_{i j}\right) \\
= & \left(1-f l_{i j}\right)+\left(1+f_{i j}\right) \\
= & 2 .
\end{aligned}
$$

Matings between unlike genotypes will be: ${ }_{m} A_{g h}$ and ${ }_{f} A_{i j}$ or ${ }_{m} A_{i j}$ and ${ }_{f} A_{g h}$.

It is assumed that these will have equal frequency, a condition not necessarily implying either randomness of mating or unity of sex ratio. The former will have relative fertility: $\left(1+{ }_{m} l_{g h}\right)+\left(1+{ }_{f} l_{i j}\right)$, and the latter: $\left(1+m l_{i j}\right)+\left(1+f_{g h}\right)$.

On Allan's hypothesis, $m l_{g h}+{ }_{f} l_{g h}=0$, and $m l_{i j}+{ }_{f} l_{i j}=0$. Therefore the mean relative fertility of these matings will be $4 / 2$ or 2 . That is, the numbers of each genotype will be constant in the next generation, whatever the gene frequencies (the equations being independent of $x_{1}, x_{2} \ldots x_{n}$ ). The stability is therefore neutral. Allan's hypothesis is not, in this interpretation, a sufficient reason for a stable variation.

(3) Bryce, Jakobowicz, McArthur, and Penrose (1950), in an analysis of 7,856 consecutive motherchild pairs of known blood group in Australia, provided evidence of a relative deficiency of Group $\mathrm{AB}$ infants and irregularities in the distribution of blood groups among the children of Group A and B mothers. These observations were considered to be suggestive of differential fertility or foetal viability, or both concordantly.

The data were analysed by calculating the expected numbers in each mother-infant phenotype pair, on the assumption that the parents were a random sample, randomly mated, from a universe whose frequencies could be accurately inferred. For the body of their table

$$
\sum \frac{d^{2}}{e}
$$

is 24.26: this has been derived from fourteen class frequencies, only one parameter, the total number, being derived from the data, the other two parameters, specifying the gene frequencies, being derived partly from the data but mainly from other data assumed to have been assembled from the same universe. The heterogeneity in the body of the table is significant at thirteen degrees of freedom $(0.01<p<0.05)$. However, differential fertility or foetal viability cannot definitely be inferred as a necessary cause, since there is evidence of a considerable, though not significant, discrepancy between the 
expected and observed numbers of children of each blood group $\left(\chi_{(3)}^{2}=6.37 ; 0.05<p<0.1\right)$, the discrepancy being almost entirely due to a shortage of infants of Group $A B$, or an excess of Group $A B$ mothers. The proportion of mothers of Group AB does not differ appreciably from that expected from the gene frequencies calculated from the other three phenotypes, nor from the proportion in the control population. The authors recognized the possibility of some systematic grouping errors, some AB infants being grouped as $\mathrm{B}$, and comparison of the number of infants grouped as $\mathrm{AB}$ with the number expected from the gene frequencies calculated from the other phenotypes suggests that such errors may be appreciable. In view of the known difficulty of detecting the $A_{2}$ antigen in group $A_{2} B$ infants, it appears reasonable to consider grouping errors* as a likely contributory cause of the observed discrepancies. The maximum likelihood estimate of this possible error, on the assumption that the children have the gene frequencies of the adult sample, is $0 \cdot 116 \pm 0 \cdot 045$ (11.6 per cent. \pm 4.5 per cent. $\mathrm{AB}$ infants grouped as $B)$. If this error were entirely due to failure to detect the $A_{2}$ antigen, it suggests that about half the infants of group $\mathrm{A}_{2} \mathrm{~B}$ were grouped as $\mathrm{B}$. If this estimate is used to calculate the expectations, the heterogeneity in the body of the table is considerably reduced,

$$
\sum \frac{d^{2}}{e} \text { being } 18 \cdot 7
$$

which, if distributed as $\chi^{2}{ }_{(12)}$ (a second parameter having been estimated from the data), is not conventionally significant $(0.05<p<0.1)$.

Although these data are very suggestive of a high fertility of Group AB women, a trend which could be a powerful influence in maintaining variation, the discrepancies are largely explicable on grounds of the technical difficulty of detecting in infancy the $A_{2}$ antigen in the presence of the $B$ antigen. $A$ follow-up of a series of infants presumed to be Group B would be of interest.

(4) Kirk, Kirk, and Stenhouse (1953) analysed the records assembled over a period of 4 years in a large Australian maternity hospital and claimed to have shown a highly significant trend in fertility, Group A women being more fertile than Group $O$ between the ages of 25 and 35, and Group $O$ women being more fertile before and after this period. They made no claim of any appreciable difference in overall fertility.

* The word "error" is unfortunate, but not easily replaced. It is merely intended to imply failure to discern the indiscernible.
Their method consisted of fitting orthogonal polynomials of unstated degree to the unweighted difference between the mean number of pregnancies of Group $\mathrm{A}$ and of Group $\mathrm{O}$ women by each age. The regression line shown in their graph does not appear to have a high significance, apparently accounting for only about half the variance. Over half the children ascribed to women over 35 were from families exceeding six children, most of whom were presumably born before their mothers reached that age, so that the inference about the differential fertilities after age of 35 were made on data largely relevant to their fertilities before this age. In fact, the 271 women delivered between the ages of 35 and 40 are credited with 1,453 children and it is these children who form the major part of the data used to establish the difference in fertility in this age group. The problem is further complicated by the fact that the delivery rate in the hospital doubled within the observation period, and that mothers in different age groups increased in very different proportions.

Their second claim is that there was a significant excess of Group $\mathrm{O}$ women among primigravidae. The discrepancy would seem to arise mainly from the extraordinary fact that over the 4-year period, during which the delivery rate doubled, Group A women had more second than first children. Since such conditions would be impossible in a stable or expanding universe there seems no likelihood of this being other than a curious sampling error. The statement that "both for women of English name and for the total Perth sample there is significant excess of Group $\mathbf{O}$ women experiencing their first pregnancy" is misleading. The discrepancies of the whole are almost entirely due to the women of English name, who form the majority (for the women of non-English name $\left.\chi_{(1)}^{2}=0.086\right)$.

The statement, which forms the premise of an argument, that Group $\mathrm{O}$ mothers experience a higher number of pregnancies before the age of 19 than Group A mothers, is not supported by the data. The number of women delivered was 139 in Group $O$ and 130 in Group $A$; expected values are 138.4 and 130.6 respectively.

The analysis of these data derived from a rapidly expanding and highly fertile population is particularly difficult, and does not convincingly demonstrate a primary influence of blood group on fertility.

(5) Johnstone (1954a) published extensive data on mother, husband, and infant phenotype trios from over 2,500 births which occurred in a West London hospital during a 13-month period. The data are 
particularly valuable because they relate to a consecutive series derived from a limited population over a short period, very few mothers therefore being represented more than omce. Husbands as well as mothers were grouped, and many trios had their Rhesus groups tested. Tube methods were used, and the fact that the number of infants of Group $\mathrm{AB}$ approximates closely to the expected number and to the number of Group AB mothers suggests that the series was not biassed by systematic grouping errors. Johnstone's analysis of the discrepancies between the expected and observed numbers in husband-wife-child phenotype classes, excluding classes with very small or clearly anomalous frequencies, led to an almost modal value for the discrepancy on the null hypothesis $\left(\chi^{2}(24)=24 \cdot 6\right)$.

A most interesting feature of the data is the large number of children whose blood groups are incompatible with those of their alleged parents. There are no fewer than seventeen bastards* detectable as such. In England the gene frequencies are such that only about 18 per cent. of agamous children can be detected by anomalies in the parent-child ABO blood groups, so that of the 2,578 matings almost a hundred, or nearly 4 per cent., are likely to be agamous.

Efficient estimation of this incidence is difficult. Every trio provides some relevant information, and usually trios with the smallest frequencies are the most informative; in addition most phenotypes contain several genotypes in unknown proportions. The most informative unions are those between recessives; in England about one-fifth of unions are $\mathrm{gg} / \mathrm{gg}(\mathrm{O} / \mathrm{O})$ and, independently, one-thirtieth are $\mathrm{dd} / \mathrm{dd}(\mathrm{rh} / \mathrm{rh})$. Assuming equal phenotype fertility and foetal viability, and the fathers of the agamous children to be almost all different, and to come from the same population, the probability of any paternal gene will be proportional to its frequency in the population. Consider the double recessive marriages, and let a proportion $\alpha$ of the children be agamous, and $D$ be the gene frequency of the dominant gene or genes considered to be known exactly $(\mathrm{D}=\mathbf{0} \cdot 3305$ in $\mathrm{ABO}$ system, $0 \cdot 5740$

* The nomenclature of such children is difficult, bastardy and illegitimacy being legally defined, and conventionally used, in relation to wedlock. It is proposed to term these children, and the union giving rise to them, agamous, as opposed to gamous children whose parents are married or living together; the many illegitimate children born of parents whose union, though stable, is not legal, may conveniently be considered gamous. The words are short, euphonious, and not grossly distorted from their natural meaning. Their occasional use in systematic botany is unlikely to cause confusion. in Rhesus), an assumption which ensures simplicity at a cost of slightly underestimating the variance of the estimate. Let $L$ children be recessive, and $B$ children dominant. Then, to estimate $\alpha$, the likelihood function will be:

$$
\mathrm{B} \log \alpha \mathrm{D}+\mathrm{L} \log (1-\alpha \mathrm{D}) .
$$

Of the 550 reputed $\mathrm{gg} / \mathrm{gg}(\mathrm{O} / \mathrm{O})$ matings in Johnstone's series, nine resulted in Group A or B children, giving an estimated proportion of agamous children of $4.95 \pm 1.63$ per cent. Of the 59 reputed $\mathrm{dd} / \mathrm{dd}$ $(\mathrm{Rh} / \mathrm{Rh})$ matings, six resulted in $\mathrm{Rh}+$ children, giving an estimate of $17 \cdot 72 \pm 7 \cdot 07$ per cent. Since very few marriages are likely to be represented in both, only about 0.7 per cent. of marriages being gg,dd/gg,dd and only about 40 per cent. of trios having been Rhesus-typed, these may be combined without gross error, giving an approximate estimate of $5.7 \pm 1.6$ per cent. This is a remarkably high figure, suggesting that agamous children may even outnumber illegitimate children. Johnstone comments that most of the known cases were first-born. If, as is probable, most of these agamous unions were prenuptial, then since only a minority of women now marry when pregnant, a very large proportion of those who do would appear not to marry the man by whom they are pregnant. If, for example 10 per cent. of first-born children were agamous and all conceived prenuptially, and 20 per cent. of women married while pregnant, half these women would not have married the man by whom they were pregnant.

Johnstone's only claim of significance relates to a shortage of Group $\mathrm{O}$ children of $\mathrm{O} / \mathrm{A}$ marriages. He has pointed out that the data collected by Hirszfeld (1928) and by Waterhouse and Hogben (1947) show a similar shortage, and their data have clearly been approached to test a single prior hypothesis. It would appear that this deficiency of Group $\mathbf{O}$ children of $\mathbf{O} / \mathrm{A}$ marriages is partly attributable to the high incidence of agamous children. This explanation, while sufficient to reduce the level of significance to that conventionally trivial, is not sufficient to allay suspicion of a real effect.

However, Johnstone's analysis of the data of Hirszfeld and of Waterhouse and Hogben is open to two criticisms. Firstly, the two sets of data contain in common the data of Hirszfeld and Hirszfeld and of Hirszfeld, Hirszfeld, and Brokman (Table III, overleaf), comprising 23 O/A marriages with 69 children; the fifteen segregating families contained 21 Group $O$ children and 32 Group A children. This considerable discrepancy has thus been counted twice. Secondly, these data refer not to single births, but to families, and, since there is complete intraclass 
correlation between the blood groups of all gamous children of $\mathrm{gg} / \mathrm{G}^{A} \mathrm{G}^{\mathrm{A}}$ marriages, the significance of the discrepancy cannot be assessed by simple tests. An exact solution, with scores, has been presented by Hogben (1932).

In Waterhouse and Hogben's data, the discrepancy is almost entirely due to the non-segregating families, the segregating families containing 272 Group $O$ children and 278 Group A children. The total discrepancy, although its significance is not easily assessed, is suggestive of a high fertility of $g g / G^{A} G^{A}$ marriages, a trend which could be a sufficient cause of a persistent variation. If this same discrepancy were evident in Hirszfeld's data, this would be confirmatory; on the other hand, if the discrepancy were of a different nature, the vagaries of sampling, mating, and grouping would appear more likely causes in the apparent absence of any single, sufficient, and reasonable biological explanation. In that part of Hirszfeld's data for which details are available, a considerable discrepancy (about twothirds of the total) is apparent in those families which segregate. Of the 142 families which contain no obviously agamous children, 72 show segregation, in which there are 131 Group $O$ and 172 Group A children. Bennett and Brandt's efficient test (Table III) gives $\chi^{2}{ }_{(1)}=8.90(0.001<p<0.01)$ with heterogeneity $\chi_{(12)}^{2}=18.42(0 \cdot 1<p<0 \cdot 2)$. The ratio of the contributions of the overall effect and the heterogeneity is also significant $(F=5 \cdot 8$, $0.01<p<0.05$ ). This does not necessarily indicate that the overall effect is significant, because the greater part of this effect may be due to the presence of agamous children and to grouping errors rather than to the non-systematic disturbances for which analysis by partitioning variance would be appropriate. The data as a whole do not reveal any significant overall effect.

Since the apparently sustained trend in the three sets of data considered by the author is not due to any consistent type of discrepancy, and is not readily accounted for by any hypothesis advanced, and since, where efficient or appropriate tests of significance have been applied on the combined data, there is no unexceptionable evidence of any shortage at even the lowest conventional level of significance, it seems that there is no inexplicable divergence from the null hypothesis of equal fertility and foetal viability of the $\mathrm{ABO}$ phenotypes.

(6) Kirk, Shield, Stenhouse, Bryce, and Jakobowicz (1955), in an analysis of a sample similar to, and partially inclusive of, that of Kirk, Kirk, and Stenhouse, drew the following conclusions:

" (i) Both in Melbourne and Perth A women had a higher average number of pregnancies than $O$ women, the difference being significant for Perth, where there was also a significant linear increase in this difference with age.

TABLE III

ANALYSIS OF SEGREGATING FAMILIES FROM O/A MARRIAGES IN THE DATA OF HIRSZFELD (1928) AND OF WATERHOUSE AND HOGBEN (1947)

(Method of Bennett and Brandt, 1955)

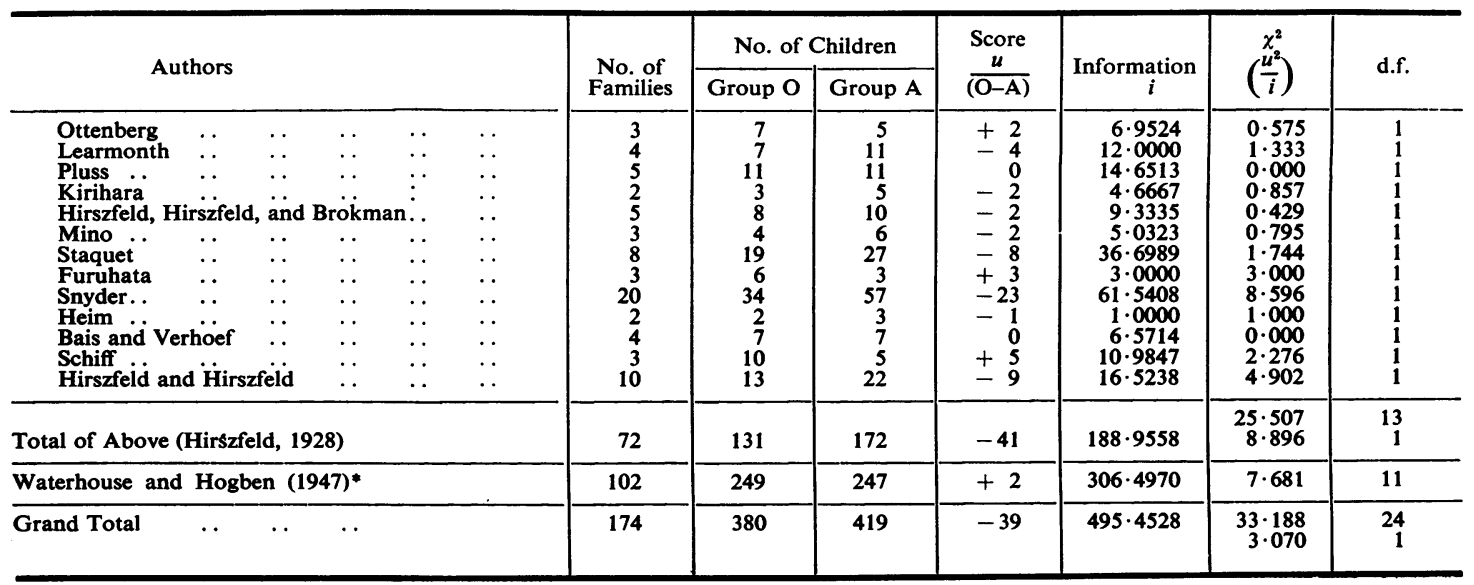

- Less the fifteen families already included in Hirszfeld's series.

From the analysis of Bennett and Brandt (1955). 
"(ii) A comparison of the calculated and observed number of children in different mother-child bloodgroup combinations for 16,179 single births in Melbourne reveals a significant deficiency of Group $A$ children to Group $O$ mothers and Group $A B$ children to Group A and B mothers, and a significant excess of Group $O$ children to Group O mothers, of Group A children to Group B mothers, and Group $B$ children to Group A mothers.

"(iii) A breakdown of mother-child blood-group combinations by birth rank reveals that the deficiency in Group A and B children to Group $O$ mothers is absent for first-born children, present for second-born children, and greatest for thirdborn children."

Their statement of the significant excess of children to Group A mothers is based on a " $t$ " test which is probably not appropriate, as the variance of the number of children per family, especially when the first is excluded, as a necessary condition of motherhood, usually greatly exceeds the mean. No details of the linear increase with age are given, but it is apparently based on the number of children born by a given age and not the number being born at that age.

Their second set of claims, although maintained at very high levels of significance, are not necessarily acceptable evidence of differing fertility, since their comparison of phenotype frequencies of mother and child $\left(\chi^{2}{ }_{(3)}=23 \cdot 22\right)$ suggests effects of such magnitude that they would have shown up in population surveys covering different generations and sexes. It seems more likely that there were systematic grouping errors. This explanation is supported by the discrepancy in blood group distribution between mothers and infants $\left(\chi_{(3)}^{2}=31 \cdot 87\right)$. If this discrepancy is examined in detail (Table IV), it is evident that the greater part is due to a shortage of Group $A B$ infants. If Groups $B$ and $A B$ are combined, an efficient estimate of the proportionate gene frequencies may be made by solving the following determinate equations, where $\mathrm{O}, \mathrm{A}, \mathrm{B}$, and $\mathrm{AB}$ are the proportionate phenotype frequencies:

$$
\begin{aligned}
r^{2} & =\mathrm{O} \\
2 p r+p^{2} & =\mathrm{A} \\
2 p q+2 q r+q^{2} & =\mathrm{AB}+\mathrm{B}
\end{aligned}
$$

These are satisfied by the values $p=0 \cdot 2420$, $q=0.0658$, and $r=0.6922$, giving the expected proportion of $\mathrm{AB}$ as $3 \cdot 185$ per cent., the observed proportion being 2.695 per cent., which implies that about 15.4 per cent. of Group AB infants were wrongly grouped as B. This estimate is similar to that obtained from Bryce and Jakobowicz's former data (11.6 \pm 4.5 per cent.). After corrrecting for grouping errors by the use of this estimate, comparison of the phenotype distributions of mothers and children shows much smaller discrepancies (Table IV).

TABLE IV

\begin{tabular}{|c|c|c|c|c|}
\hline $\begin{array}{l}\text { Blood } \\
\text { Group }\end{array}$ & $\begin{array}{l}\text { No. of } \\
\text { Mothers }\end{array}$ & $\begin{array}{l}\text { No. of } \\
\text { Children }\end{array}$ & $x^{2}$ & $\left.\stackrel{\chi^{2}}{\text { (corrected }}{ }^{*}\right)$ \\
\hline $\begin{array}{c}\mathbf{O} \\
\mathbf{A} \\
\mathbf{B} \\
\mathbf{A B}\end{array}$ & $\begin{array}{r}7,585 \\
6,406 \\
1,605 \\
583\end{array}$ & $\begin{array}{r}7,752 \\
6,369 \\
1,622 \\
436\end{array}$ & $\begin{array}{r}1 \cdot 818 \\
0.107 \\
0.090 \\
21 \cdot 206\end{array}$ & $\begin{array}{l}1 \cdot 818 \\
0 \cdot 107 \\
1 \cdot 221 \\
4 \cdot 211\end{array}$ \\
\hline Total & 16,179 & 16,179 & $23 \cdot 221$ & $7 \cdot 357$ \\
\hline
\end{tabular}

DISTRIBUTION OF MOTHERS AND CHILDREN ACCORDING TO BLOOD GROUP

When $\chi^{2}(3)=23.221, p<0.001$

$\chi^{2}(2)=7.357,0.01<p<0.05$

- Corrected for estimated grouping errors.

The discrepancies remaining are due to an excess of children of Group $\mathbf{O}$ and a deficiency of Groups $A, B$, and $A B$. This is not unexpected, since the data relate to at least two racial sub-groups with different gene frequencies, and since mating is assortative (as is demonstrated by the different gene frequencies of mothers with and without English names) the children would be expected to contain an excess of homozygous individuals over those calculated on the assumption of random mating. For the same reason gene frequencies calculated as above, on the assumption of random mating (or random pairing of allelomorphs), and any estimate based on this calculation, must be regarded as approximate. Both assortative mating and grouping errors would lead to an apparent deficiency in the observed numbers of Group $A B$ infants.

Their third claim regarding the influence of birth rank on infant blood group cannot be regarded as clearly demonstrated if consideration is extended to the higher birth ranks. The relevant data (Table V, overleaf), although showing an apparent loss of incompatible children in the second and third birth ranks, do not show any consistent trend when viewed as a whole.

(7) Matsunaga (1953) and Matsunaga and Itoh (1953) in Japan, have made the only large surveys on entire families within defined districts. Since the districts were uniform for race and the families were large, these data would be of extreme value, but unfortunately only a part has so far been published. This shows an extreme impairment in fertility 
TABLE V

FREQUENCY OF INCOMPATIBLE CHILDREN* ACCORDING TO BIRTH RANK

\begin{tabular}{c|c|c|c|c}
\hline \multirow{2}{*}{$\begin{array}{c}\text { Birth } \\
\text { Rank }\end{array}$} & \multicolumn{3}{|c|}{ No. of Children } & $\begin{array}{c}\text { Percentage of } \\
\text { Incompatible } \\
\text { Children }\end{array}$ \\
\cline { 2 - 3 } 1 & Compatible & Incompatible & Total & \\
\hline 2 & 2,113 & 488 & 2,601 & $18 \cdot 8$ \\
3 & 1,930 & 436 & 2,366 & $18 \cdot 4$ \\
4 & 1,221 & 639 & 1,454 & $16 \cdot 0$ \\
5 & 690 & 784 & $18 \cdot 5$ \\
and Over & 690 & 160 & 850 & $18 \cdot 8$ \\
\hline Total & 6,593 & 1,462 & 8,055 & $18 \cdot 2$ \\
\hline
\end{tabular}

* An incompatible child is one who would be incompatible (relative to the ABO system) as a blood donor to his mother.

and infant viability within heterospecific marriages, an effect which, it is suggested, may be balanced by mutation.

Some of their data are more widely known (Matsunaga, 1955) and are said to imply a significant deficiency of Group A children of Group $\mathbf{O}$ mothers and Group A fathers, and of Group B children of Group $\mathbf{O}$ mothers and Group B fathers. However, the significance has not yet been rigorously demonstrated, since the tests assume the proportion of homozygous fathers to have zero sampling variance, the distribution of family size to be Poissonian, and husbands to be synonymous with fathers. The apparent increase in abortion rate in heterospecific marriages assumes that a woman who has had one abortion is not more likely to have another. The data are such that no reasonable interpretation or informed criticism can precede complete publication.

\section{A Critical Examination of Published Work claiming an Association between Blood Group and Sex-Ratio}

The influence of parental blood groups on the sex-ratio of children, which may be regarded as a particular form of differential fertility, has been the subject of three widely-quoted reports:

(1) Sanghvi (1951) claimed consistent significant discrepancies on two mother-child series, one of 1,330 Indian births, the other of 865 births in New York. When each series is analysed as a whole, the data, excluding phenotype pairs of low frequency, do not show any significant heterogeneity $\left(\chi^{2}{ }_{(13)}=\right.$ 13.9 for the Indian series and $\chi^{2}{ }_{(6)}=9.9$ for the New York series).

However, Sanghvi has not made this analysis, but has analysed only those classes in the body of the table which are "large enough for further consideration". If these classes were selected purely on grounds of size, the chance that the difference between the outlying pair would be significant at the $p^{\text {th }}$ level considerably exceeds $p$. With such large numbers, in any class frequency the probability distribution of $\frac{d}{\sqrt{ } e}$ will be approximately that of a random sample from a normal variate of unit variance, and the range of the extremes in such cases has been tabulated (May, 1952). The range of three such samples which will just not be exceeded in 5 per cent. of cases is 3.32 units, and a $2 \times 2 \chi^{2}$ estimation will be at least $2\left(\frac{1}{2} \times 3 \cdot 32\right)^{2}$ or $5 \cdot 51$, in 5 per cent. of cases. Sanghvi's value of $\chi_{(1)}^{2}=5 \cdot 57$ is possibly just significant at this level. The New York data where then examined in the light of this prior hypothesis, which was confirmed, $\left(\chi_{(1)}^{2}=4 \cdot 93\right)$, although the high overall sex-ratio possibly impairs any assumption of generality.

This appears to be the only rigorously demonstrated discrepancy in relation to sex-ratio and blood group. However, in view of the failure of more recent work to confirm these findings, it appears likely that this promising start was due to the fact that when tests are used to assess significance at the 5 per cent. level, 5 per cent. of null hypotheses will inevitably be wrongly rejected through chance alone.

(2) Johnstone (1954b) published data referring to 3,791 children of 2,100 marriages, the sexes of the children and the blood groups of both parents being known. This is by far the most informative series yet published. Having noted that the sex-ratio of infants of Group B mothers was high, while that of Group B fathers was low, he picked out for special attention the two marriage classes $B /$ not- $B$ and not-B/B and found a difference in the sex-ratio of the children which almost reached the conventional threshold of significance $\left(\chi^{2}(1)=3 \cdot 799\right)$. Little importance can be attached to this result, however, since numerous equally reasonable comparisons could have been made. For example, if fourteen appropriate independent comparisons could be made, there would usually be at least one "statistically significant" discrepancy, even if there were no association between sex-ratio and blood group.

A further analysis of the B/not-B marriages by birth rank has inevitably led to discrepancies which appear to be even more significant. As there are several possible comparisons, the highly significant discrepancy reputed to occur between the sex-ratios of first children of the reciprocal marriage pairs cannot be accepted; and since it is a posterior hypothesis unsupported by exterior evidence or by any explanatory mechanism it must provisionally be considered as a vagary of sampling. The data as a whole, excluding three phenotype pairs with less than ten 
children of either sex, do not reveal any significant heterogeneity $\left(\chi^{2}{ }_{(12)}=15 \cdot 9\right)$.

(3) Cohen and Glass (1956), in an analysis of an extensive series of mother-child phenotype pairs assembled in Baltimore, were unable to demonstrate any significant association with sex-ratio. They pointed out that Johnstone's data showed no discrepancy when similarly analysed, and this absence of any significant discrepancy persisted after his data were combined with theirs. But the addition of Sanghvi's data from New York and Bombay enabled them to demonstrate highly significant discrepancies in a large number of comparisons; in particular, the sex-ratio was low in offspring of Group A mothers and in Group A offspring, and was high in offspring of Group B mothers and in Group B offspring.

The discrepancies found are not other than those to be expected if data from Baltimore and Isleworth are combined with data from Bombay, since in the Indian data the sex-ratio was very high $(54.6$ per cent.), and the frequency of Group B. relative to Group A much higher than in the British and American data. Consequently the infants of Group B mothers and the Group B infants contain a disproportionate number of Indians, who are poorly represented among both infants of Group A mothers and Group A infants. The data of Sanghvi are said not to differ significantly from those to which they were added $\left(\chi_{(28)}^{2}=25 \cdot 44\right)$, but as a similar test for homogeneity of the Baltimore sample gave the almost impossible result $\chi^{2}{ }_{(14)}=0.67(p>0.999999)$, this claim of homogeneity cannot be accepted. As the sex-ratio and the proportions of the various blood groups in the Indian and not-Indian data differ significantly and considerably, to an extent and in a direction sufficient to explain the overall heterogeneity, the analysis of the data cannot be accepted as necessarily implying any primary relationship of $\mathrm{ABO}$ phenotype and sex-ratio.

\section{SUMMARY}

Evidence is advanced that grouping errors (over 10 per cent. of Group AB infants being grouped as $B$ in two series) and paternity errors (over 5 per cent. of children being not fathered by their mother's husband in one series) are so common as greatly to complicate any analysis of data suggestive of a relationship between fertility and blood group.

It is concluded, for these and other reasons, that there has not yet been any satisfactory demonstration at the statistical level of any differences in fertility or sex-ratio primarily related to the $\mathrm{ABO}$ blood groups.

The apparent absence of any statistical evidence is probably quite compatible with differences in fertility sufficient to maintain the variation in the ABO phenotypes.

\section{REFERENCES}

Allan, T. M. (1953). British Journal of Preventive and Social Medicine, 7,220

Bennett, J. H. and Brandt, J. (1954). Ann. Eugen., (Camb.) 18, 302.

British Medical Journal, 1, 1197 (Annotation).

Bryce, L. M., Jacobowicz, R., McArthur, N., and Penrose, L. S. (1950). Ann. Eugen. (Camb.), 15, 271.

Cohen, B. H., and Glass, B. (1956). Hum. Biol., 28, 20.

Glass, B. (1950). Amer. J. hum. Genet., 2, 269.

Haldane, J. B. S. (1956). Ann. hum. Genet., 20, 309.

Hirszfeld, L. (1928). "Konstitutionsserologie und BlutgruppenForschung". Springer, Berlin.

Hogben, L. (1932). J. Genet., 25, 211.

Huxley, J. (1955). Heredity, 9, 1 .

Kirk, R. L., Kirk, M., and Stenhouse, N. S. (1953). British Journal of Preventive and Social Medicine, 7,1 .

Kirk, R. L., Shield, J. W., Stenhouse, N. S., Bryce, L. M., and Jacobowicz, R. (1955). Ibid., 9, 104.

Johnstone, J. M. (1954a). Ibid., 8, 117.

- (1954b). Ibid., 8, 124.

Matsunaga, E. (1953). Proc. Jap. Acad., 29, 399.

Matsunaga, E. (1955). Amer. J. hum. Genet., 7, 66. - (1955). Amer. J. hum. Genet., 7, 66. $29,529$.

May, J. M. (1952). Biometrika, 39, 192.

Penrose, L. S. (1955). Personal Communication.

Sanghvi, L. D. (1951). Nature (Lond.), 168, 1077.

Waterhouse, J. A. H., and Hogben, L. (1947). British Journal of Social Medicine, 1, 1 .

Woolf, B. (1955). Ann. Eugen. (Camb.), 19, 251. 